\title{
UMA ANÁLISE DAS REPRESENTAÇÕES DE ARTEMÍSIA GENTILESCHI (1593-1654) EM ESTUDOS DE CARÁTER BIOGRÁFICO
}

\section{AN ANALYSIS OF THE REPRESENTATIONS OF ARTEMISIA GENTILESCHI (1593-1654) IN BIOGRAPHICAL STUDIES}

Cristine Tedesco ${ }^{1}$

\section{RESUMO}

Este trabalho propõe uma análise das representações de Artemísia Gentileschi (15931654) na historiografia da arte italiana recente, considerando, principalmente, os capítulos respectivamente intitulados: "Fino a qual segno giungessel'ingegno, e la mano d'una tal donna": geografia e rango diArtemisiaGentileschi e Ritorno a Roma: 1620-1627, dos pesquisadores Roberto Contini e Francesco Solinas - os quais têm se dedicado ao estudo da vidobra da pintora nas últimas três décadas. Os capítulos estão publicados no catálogo referente à exposição ArtemisiaGentileschi:Storiadi una passione realizada em Milão (2011-2012). Tendo em vista o caráter biográfico dos estudos de Contini e Solinas, nosso objetivo é discutir como a trajetória de Artemísia é representada ao longo dos textos, problematizando também, em que medida as questões gênero, ilusão biográfica e redes de relações são preocupações apresentadas nos dois capítulos. Além disso, a partir da trajetória Artemisia Gentileschi o trabalho realiza uma investigação acerca da rede de relações construída pela pintora nas cortes e instituições nas quais atuou na primeira metade do século XVII. Problematizando as normas sociais e a cultura do período, o trabalho discute como Artemisia e outras mulheres artistas de seu tempo se inseriram e atuaram no mundo da produção artística. Enquanto as normas sociais do período tornavam difícil o aprendizado e a profissionalização das mulheres, em especial no campo da produção artística, ao mapearmos as fontes nos deparamos com uma atuação significativa das mulheres no mundo da criação. A partir das trajetórias que revelam a atuação feminina na produção artística, nos perguntamos que outras histórias podemos escrever: uma outra história da arte, da pintura e das mulheres, tendo em vista limites mais flexíveis para as fronteiras de gênero.

Palavras-chave: Gênero. Mulheres artistas. Trajetória. Estudos biográficos.

${ }^{1}$ Doutoranda do Programa de Pós-Graduação em História da Universidade Federal do Rio Grande do Sul. Bolsista CAPES. E-mail tedesco.cristi@gmail.com; Porto Alegre, Brasil. 


\begin{abstract}
This work proposes an analysis of the representations of Artemisia Gentileschi (15631654) in the recent Italian art historiography, considering mainly the chapters respectively entitled: "Fino a qual segno giungessel'ingegno, e la manod'unatal donna": geografia e rango di Artemisia Gentileschi e Ritorno a Roma: 1620-1627, written by the researchers Roberto Contini and Francesco Solinas - who have been dedicated to the study of the painter's vidobra in the last three decades. The chapters are published in the Artemisia Gentileschi: Storia di una passione catalogue, an exhibition which took place in Milan (2011-2012). Considering the biographic nature of Contini and Solinas' studies, our goal is to discuss how Artemisia's trajectory is represented by the texts, problematizing how the questions of gender, biographical illusion and relationship networks are concerns presented in both chapters. Furthermore, from the analysis of the trajectory of Artemisia Gentileschi (1593-1654), the work performed an investigation about the relationships network built by the painter in the courts and institutions in which she has worked in the first half of the Seventeenth century. By problematizing the social rules and the culture of the period between the Sixteenth and the Seventeenth century, the article discusses how Artemisia and other female artists of her time have inserted themselves in the world of artistic production and how they have acted in that world. While the social rules of the period made women's learning and professionalization harder, especially in the field of artistic production, when we mapped the sources we came across several women that have had a significant role in the world of creation.Looking at thethe trajectories that reveal women's role in artistic production, we ask ourselves what other histories we can write: another history of art, of painting and of women, having in sight the more flexible limits for the borders of gender.
\end{abstract}

Keywords: Gender. Women Artists. Trajectory. Biographical Studies. 


\section{Introdução}

Este trabalho apresenta alguns resultados de estudos de caráter biográfico, produzidos pelo campo da historiografia da arte italiana recente sobre a pintora Artemísia Gentileschi (1593-1654).Os textos analisados foram publicados no catálogo "Artemisia Gentileschi. Storiadi una passione" "referente à exposição ${ }^{3}$ realizada no Palazzo Reale, em Milão, entre os anos de 2011 e 2012.Analisaremos os capítulos dos organizadores da obra: Roberto Contini e Francesco Solinas, intitulados: "Fino a qual segno giungessel'ingegno, e la mano d'una tal donna": geografia e rango di Artemisia Gentileschi e Ritorno a Roma: 16201627. O catálogo ainda publicou textos dos pesquisadores: Judith W. Mann, Luciano Arcangeli, Mina Gregori, Renato Ruotolo, Roberto Paolo Ciardi, Rodolfo Maffeis, os quais também desenvolvem uma escrita de caráter biográfico. Além disso, o catálogo apresenta um estudo cronológico exaustivo acerca da trajetória de Artemísia Gentileschi, realizado por Michele Nicolaci e Yuri Primarosa.

Tendo em vista a relevância dos estudos sobre Artemísia, realizados pelo campo da historiografia da arte, nosso objetivo é discutir como a trajetória da pintora é representada ao longo dos textos de Roberto Contini (2011) e Francesco Solinas (2011a), problematizando em que medida as questões gênero, ilusão biográfica e redes de relações entre sociedade e indivíduos são preocupações apresentadas nos dois capítulos.

\section{Mulheres artistas e a escrita de caráter biográfico}

Os estudos de caráter biográfico sobre mulheres artistas têm se tornado cada vez menos discretos na historiografia da arte. Podemos mencionar algumas dessas mulheres, cuja produção bibliográfica a seu respeito é expressiva e que foram contemporâneas de Artemísia Gentileschi (1593-

${ }^{2}$ CONTINI, Roberto; SOLINAS, Francesco. (Org.). Artemisia Gentileschi.Storiadi una passione. Catalogo della mostra.Milano: 24 ORE Cultura, 2011a.

${ }^{3}$ A Mostra Artemisia (2011-2012) foi uma exposição que não apenas destacou a produção da pintora, mas, sobretudo, revelou que Artemísia sabia trabalhar, com grande qualidade, uma variedade de gêneros pictóricos e temas muito amplos. Cinquenta pinturas da artista romana apresentadas nesta exposição, pela primeira vez juntas em um espaço, junto às de seu pai (Orazio Gentileschi), tio (Aurelio Lomi) e de alguns pintores que trabalharam com Artemísia, por exemplo, Simon Vouet, e que fazia parte de sua oficina, como Bernardo Cavallino. As pinturas de Artemísia produzidas na primeira metade do século XVII, reunidas nessa exposição, estão atualmente em acervos de museus, galerias de arte e coleções particulares em países como Itália, Estados Unidos, Hungria, Inglaterra, Espanha, França. A exposição foi organizada pelos historiadores da arte Roberto Contini e Francesco Solinas no PalazzoReale, em Milão, entre setembro de 2011 e janeiro de 2012. 
1654), a exemplo das pintoras Lavínia Fontana (1552-1614), Elisabetta Sirani(1638-1665) e Sofonisba Anguissola (1531-1621).

Lavínia Fontana (1552-1614) nasceu em Bolonha, foi discípula do pai Próspero Fontana - estudou anatomia no ateliê do mesmo. Casou-se com Giovan Paolo Zappi, um dos discípulos de seu pai, o qual não teria colocado obstáculos ao seu trabalho como pintora, conforme Alberto Manguel (2001). Produziu telas e retábulos, retratos e nus. O mesmo autor ainda ressalta que Lavínia Fontana, “[...] estabeleceu relações intelectuais no exterior e, por intermédio de recomendações de vários notáveis de Roma, foi nomeada pintora de Gregório XIII e sua família, os Boncompagni” (MANGUEL, 2001, p. 135).

No que diz respeito à atuação de Lavínia Fontana no cenário artístico, Vicenzo Golzio (1950), destaca sua participação, também, nas pinturas de capelas:

Entre 1611 e 1614, era construída com desenhos da Modernidade a Capela Maior de Santa Maria da Paz, e Albani foi chamado para decorar uma parte, enquanto o resto era pintado por Lavínia Fontana e Domenico Passignano. Albani fez nos ângulos do arco a figura dos profetas em volta da Assunção da Virgem, nas janelas alguns anjos, nos quatros ângulos em volta dos anjos, músicos, e finalmente, no espaço debaixo do altar, o Pai Eterno. Esta obra foi elogiadíssima pelos contemporâneos porque foi feita com grande perfeição, tanto no desenho como no colorido ${ }^{4}$ (GOLZIO, 1950, p. 470).

Ao comentar a atuação de Lavínia na produção da arte, Carlo Cesare Malvasia (1678) cita uma série de igrejas e capelas para as quais a pintora produziu não apenas retratos, mas também altares. $\mathrm{O}$ autor ainda lembra que a Academia de Roma dedicou uma coletânea de rimas em louvor à pintora. Exaltada por literatos como o bolonhês Ridolfo Campaggi (1565-1624), Lavínia Fontana teve sua obra homenageada em dois poemas intitulados respectivamente "Herodiade com a cabeça de São João Batista, de Lavínia Fontana” e "À Senhora Lavínia Fontana, pintora famosíssima", ambos publicados no trabalho de Carlo Cesare Malvasia (1678, pp. 221-222).

${ }^{4}$ Frail 1611 e il 1614 venivacostruitacoidisegnidel Moderno laCapella Maggiore di Santa Maria della Pace, e l'Albani fu chiamato a decorare una parte, mentreil resto venivadipinto da Lavinia Fontana e da Domenico Passignano. L' Albani vi fecenegliangolidell'arconele figure dei profetinella volta l'AssunzionedellaVergine, sullefinestrealcuniputti, neiquattroangolidella volta degliangelimusicanti e finalmente nellalunetta sopra l'altarel'Eterno Padre. Quest'opera fu dai contemporaneilodatissimaperchécondottacon grande perfezione, tanto neldisegnochenelcolorito (GOLZIO, 1950, p. 470). (Tradução de minha autoria). 
O biógrafo e historiador da arte italiano Filippo Baldinucci (1624-1697), cujo trabalho inspira-se em Giorgio Vasari, desenvolveu um estudo renovando e expandindo as biografias deste e adicionando alguns artistas omitidos pela obra de Vasari. Baldinucci (1728, p. 96) dedica algumas páginas de seu texto à Lavínia Fontana. Para o biógrafo, a artista foi mulher virtuosa e excelente pintora; muito aplaudida, foi convidada a atuar em Roma, durante o Pontificado de Clemente VIII ${ }^{5}$, para onde se mudou em 1603; além do retrato do papa, produziu muitos retratos para cardeais, bispos, príncipes e damas. Conforme Baldinucci, Lavínia Fontana “[...] recebeu grande crédito, em parte, pela maravilha que carregam suas pinturas feitas por mãos femininas" (BALDINUCCI ,1728, p. 96).

Lembrando o capítulo de Vasari sobre a "excelente escultora Properzia de Rossi", Carlo Cesare Malvasia também escreve sobre a pintora Elisabetta Sirani (1638-1665) exaltando sua "[...] virtude incomum, humildade incomparável, modéstia indescritível e bondade inimitável ${ }^{6}$ " (MALVASIA, 1678, p. 454). A morte precoce de Elisabetta, aos 27 anos, causou grande comoção em Bologna. Filha primogênita do pintor Giovanni Andrea Sirani (1610-1670), tornou-se mais famosa que o pai, trabalhando no ateliê Sirani.

Admirador da obra da pintora, Malvasia afirma ter recebido manuscritos de Elisabetta, que lhe teriam sido entregues pelo próprio pai da pintora, os quais "[...] aqui transcrevo palavra por palavra" (MALVASIA, 1678, p. 454). De acordo com o mesmo autor, o manuscrito havia sido intitulado: "Nota das pinturas feitas por mim Elisabetta Sirani""; em suas primeiras linhas constava: "Nasci eu no dia oito de janeiro, sexta-feira, entre as seis e as sete horas, 1638 e fui levada ao batismo pelo ilustríssimo Senhor Senador Saulo Guidotti" "(MALVASIA, 1678, p. 454). Em relação à procedência da fonte transcrita pelo autor, Floriana Conte (2013) salienta “A autenticidade de tal documento publicado por Malvasia, [Felsinapittrice, 1678] do qual não se conhece o original, não foi colocada em dúvida. A Nota de Elisabetta é citada regulamente na bibliografia sobre a pintora como fonte confiável $^{10 "}$ (CONTE, 2013, p. 189).

\footnotetext{
${ }^{5}$ Ippolito Aldobrandini (1536-1605), foi papa entre 1592 e 1605. Ver:BUFFON, Dolvino Antônio.Papas: biografias.Porto Alegre: EST, 1999.

6 Tradução de minha autoria.

7 Tradução de minha autoria.

${ }^{8}$ Nota dellepitturefatte da me, ElisabettaSirani. Tradução de minha autoria.

${ }^{9}$ Tradução de minha autoria.

10 Tradução de minha autoria.
} 
É possível encontrar na listagem de Elisabetta Sirani, publicada na obra de Malsavia, aproximadamente 175 obras produzidas entre 1655 e 1665; são retratos, muitas vezes de figuras inteiras, temas da mitologia, temas bíblicos, imagens dos doze apóstolos, de santos, santas e madonas. As obras foram produzidas para colecionadores particulares, sacerdotes e nobres, bem como para altares de igrejas e capelas de Bologna e de outras regiões da Península Itálica ${ }^{11}$. Carlo Cesare Malvasia (1678) salienta que, pelo curto tempo de vida de Elisabetta Sirani, é significativo o número de obras da pintora. A produção de Elisabetta era registrada como obra do ateliê Sirani e os pagamentos pelos trabalhos eram feitos através de presentes como ouro, joias e similares, os quais o pai depositava num armário com o intuito de mostrar o sucesso da filha ao público. Junto à listagem das imagens também há alguns relatos de Elisabetta.

Conforme a transcrição de Malvasia, Elisabetta Sirani escreve sobre os fatos ocorridos no dia 13 de maio de 1664,

\section{[...] veio à nossa casa o Sereníssimo Cosme Gran Príncipe da Toscana para ver as minhas pinturas. Eu, em sua presença, trabalhava num quadro para o Príncipe Leopoldo, seu tio, no qual aludindo às três particulares virtudes daquela grande Casa [os Medici] vem a Justiça assistida pela Caridade e pela Prudência, esboçando bem próximo o menino que é amamentado pela Caridade. Me ordenou [Cosme] no fim, uma para si mesmo. Eu a fiz rápido, em tempo, que no dia que retornou a Florença estava seco"12.}

Em homenagem à Elisabetta Sirani foi publicado, no mesmo ano de sua morte, em 1665, um texto intitulado Il pennellolagrimato ${ }^{13}$, que consiste em uma oração fúnebre de Gio Luigi Picinardi que exalta, ao longo de vinte e três páginas, a atuação de Elisabetta como pintora junto ao ateliê do pai, “[...] prodígio da arte, glória do sexo feminino, joia da Itália, sol da Europa: Elisabetta Sirani” (PICINARDI, 1665, p. 4). Dentre os inúmeros elogios e exaltações ao longo da oração, o mesmo autor salienta duas características da pintora: a velocidade do trabalho de Elisabetta na produção das telas e sua graciosidade "[...] embora manuseando pinceis, parecia gracejo de fada em vez de pintura" (PICINARDI, 1665, p. 17). Na mesma obra foram publicados ainda, trinta e quatro poemas de diversos admiradores da pintura de Elisabetta Sirani, nobres bolonheses, senadores, artistas, escritores, poetas, acadêmicos e literatos.

11 Informações trazidas pela fonte "Nota de Elisabetta Sirani”"(MALVASIA, 1678, pp. 467-476).

12 "Nota de Elisabetta Sirani" (MALVASIA, 1678, p. 473-474).

${ }^{13}$ As lágrimas do pincel. (Tradução de minha autoria). 
Entre os estudos sobre mulheres pintoras no período entre os séculos XVI e XVII, também destacamos a pesquisa desenvolvida por Daniela Pizzagalli (2003). A autora nos apresenta a pintora Sofonisba Anguissola (1531-1621). Nascida em Cremona, a artista foi uma importante retratista em Gênova e Palermo. Atuou como pintora na corte espanhola de Filipe II e foi instrutora de arte da rainha Isabel de Valois. Destacouse principalmente na produção de retratos e autorretratos. Para a mesma autora,

\begin{abstract}
Ainda se o pai, com a torção do busto pro filho homem [aqui se trata de uma expressão, que pode ser entendida como se inclinar, ou dar mais atenção ao filho homem], indica uma predileção de natureza dinástica, não deveria se espantar que, na família Anguissola, a importância das mulheres fosse diminuída: mas pelo contrário, os dois homens passarão toda a vida à sombra do prestígio de Sofonisba - a primeira mulher italiana a conquistar fama internacional com a pintura -, e em parte também das duas irmãs, seguidoras de seu exemplo ${ }^{14}$ (PIZZAGALLI, 2003, p. 15).
\end{abstract}

De acordo com Pizzagalli (2003), na primeira metade década de 1620 chegou à cidade de Palermo, localidade na qual Sofonisba vivia no período, a convite do vice-rei de Nápoles, o jovem pintor flamengo Antônio van Dicky. O artista emergente solicitou uma entrevista com a pintora Sofonisba Anguissola. Na ocasião van Dicky produziu um retrato da artista, já em idade avançada.

Para analisar as trajetórias dessas pintoras, aqui mencionadas, é importante levar em consideração algumas questões sobre as dificuldades de ingresso das mulheres no mundo da criação artística. O trabalho de Linda Nochlin (1971) destaca alguns dos obstáculos socialmente impostos às mulheres artistas, como, por exemplo, a falta de acesso ao nu humano, que acabava limitando suas produções a gêneros como natureza morta e retratos. Nesse sentido, Filipa Lowndes Vicente (2005) explica que no período entre os séculos XVI e XIX, "os gêneros artísticos mais prestigiados pressupunham um domínio do corpo humano, que dependia de uma aprendizagem direta do mesmo" (VICENTE, 2005, p. 210). A mesma autora ressalta que "desde o século XIII e até recentemente, a tipologia de artista-filha-de-pai-artista, ou então filha de pai especialmente atento à sua educação assumiu um padrão persistente" (VICENTE, 2005, p. 210).

\footnotetext{
${ }^{14}$ Anche se il padre, conlatorsionedel busto verso ilfigliomaschio, indica una predilezionedi natura dinastica, no si deve temerechenella famiglia Anguissolal'importanzadellefemmine fosse sottovalutata: anzi, i dueuominipasserannotuttalavitaall'ombradel prestigio diSofonisba - la prima donna italiana a conquistare fama internazionale com lapittura - e in parte anchedellesorelle, avviatesulla sua scia (PIZZAGALLI, 2003, p. 15). (Tradução de minha autoria).
} 
O caso de Artemísia Gentileschi (1593-1654), nos ajuda a pensar essas questões. Filha de um artista, o pintor maneirista Orazio Gentileschi (1563-1639), Artemísia teve acesso ao ateliê do pai, no qual trabalhou também como modelo. Contudo, o acesso ao nu se dava através de seu próprio corpo, conforme Judith Mann (2011). Suas primeiras produções revelam a perspectiva do autorretrato, mesmo quando pintou heroínas bíblicas do Antigo Testamento. Provavelmente foi a partir de seu corpo que Artemísia idealizou imagens como Susana [no banho] e os velhos, Judite degolando Holofernes e A Virgem amamentando o Menino, produzidas antes de sua partida para Florença, em 1613.

Para além do exemplo de Artemísia, há diversos casos de mulheres artistas do século XVI ao XIX que, em vida, tiveram tudo aquilo que se considera essencial para a consolidação de uma carreira artística, “[...] críticas positivas, comissões nacionais e internacionais, valores de vendas dos quadros muito elevados, medalhas ou prêmios oficiais, reconhecimento entre os pares. Porém, mais tarde, a história encarregouse de silenciá-las" (VICENTE, 2005, p. 213).

Para Filipa Lowndes Vicente (2005), o gênero é determinante nesse processo de exclusão e ocorre por duas vertentes principais.

\footnotetext{
Em primeiro lugar, as condicionantes socioculturais que afetaram especificamente cada mulher artista. [...] A identidade de artista estava sempre condicionada pela identidade de ser mulher. Ter nascido mulher foi sempre um entrave ao ser artista: a falta de acesso ao ensino artístico ou às possibilidades de viajar, das condicionantes sociais à profissionalização feminina, sem esquecer o peso as responsabilidades familiares (VICENTE, 2005, p. 214).
}

Em segundo lugar, o fator que também contribuiu para determinar o gênero como fator de exclusão, segundo a mesma autora, foi a própria produção do século XIX, na qual consolidou-se uma história da arte que definiu aquilo que considerou digno de ser estudado. Uma história da arte enraizada em obras como a de GiogioVasari (1511-1574), reafirmando os conceitos de genialidade, originalidade, qualidade, estilos, etc. Para Vicente (2005), podemos acrescentar a estes instrumentos de análise o da masculinidade da criação artística. "As mulheres artistas constituem a exceção à norma. Encontram-se determinadas por aquilo que poderíamos denominar as 'reservas' da história da arte em integrá-las no seu discurso escrito e visual" (VICENTE, 2005, p. 214). Reservas num duplo sentido, segundo Filipa Vicente (2005); reservas dos museus como espaços de preservação, mas não de estudo científico e visibilidade destinado às mulheres artistas, tendo em vista os critérios do cânone artístico; e as reservas da própria disciplina da história da arte relativamente ao "não 
assunto" das mulheres e da arte. Nessa perspectiva as mulheres artistas estariam sujeitas a um duplo processo de exclusão, o da história vivida e o da história construída, salienta Filipa L. Vicente (2005).

Na região da Península Itálica existe uma tradição histórico-biográfica baseada no modelo "vidas de artistas" de Vasari, que privilegia os estudos sobre o desenvolvimento artístico. Além disso, o mecenato e a constituições de coleções artísticas também favoreceram essa tradição italiana na produção de textos de caráter biográfico. Filipa L. Vicente afirma que esses fatores, quando associados, ajudam a entender porque hoje sabemos um pouco mais sobre as mulheres artistas italianas do que sobre suas congêneres do norte da Europa (VICENTE, 2005, p. 218).

O crescimento da participação feminina na profissão artísticas na Europa no período entre os séculos XV e XVII é resultado de uma mudança no status das mulheres na vida social, conforme Consuelo Lollobrigida (2012). A pesquisadora lembra que no tratado De Pictura de Leon Battista Alberti, publicado em $1435^{15}$, a pintura é dividida em categorias. A pintura a partir de temas históricos que, por seu valor didático, é considerada a mais relevante, seguida pelos retratos, temas da vida cotidiana, paisagens e natureza morta.

Lollobrigida (2012) salienta que as produções artísticas de temas históricos compreendiam o rigoroso estudo do corpo humano, primeiramente com cadáveres, depois com modelos vestidos e, em seguida, com maior ênfase o estudo do nu masculino; além disso, o artista também era fortemente incentivado a viajar para os centros artísticos mais importantes para conhecer as obras dos artistas de gerações anteriores. Contudo, as mulheres estavam relegadas aos gêneros menores da profissão, porque o estudo do corpo masculino nu, vivo ou morto, era considerado indecoroso; as mulheres não eram autorizadas a viajar sozinhas, mesmo que fosse para fins de estudos. Conforme Lollobrigida (2012), "era considerada ameaçadora a atuação de mulheres que queriam libertar-se dos papéis aos quais tinham sido relegadas por séculos" (LOLLOBRIGIDA, 2012, p. 5).

A mesma autora também destaca que a literatura dedicada ao papel das mulheres na sociedade colocava em evidência as limitações que prejudicavam o amadurecimento de qualquer habilidade artística e intelectual que possuíam. Até meados do século XVI, as mulheres que pertenciam às classes menos privilegiadas, enquanto desfrutavam de uma certa liberdade de movimento e de ação, por outro lado, eram

15 Utilizamos a edição publicada em língua portuguesa: ALBERTI, Leon Battista. Da pintura. Tradução Antônio da Silveira Mendonça. 2 ed. Campinas: Unicamp, 1999. 
prejudicadas pelo cansaço, pelos perigos físicos da maternidade e pelo duro e incessante trabalho indispensável para fornecer à família as necessidades elementares da vida (LOLLOBRIGIDA, 2012, pp. 5-6).

Na segunda metade do século XVI se observam algumas modificações na situação das mulheres nas atividades artísticas. Um lento processo tornase visível por meio da atuação de mulheres como "sócias" em atividades do marido ou do pai, o que ocorreu com Diana Ghisi, Anna Maria Vaiani e Virginia dalVezzo, por exemplo, de acordo com Consuelo Lollobrigida (2012). No século XVII já encontramos casos de mulheres artistas que conduziram suas vidas de forma mais independente em relação aos períodos anteriores, como as pintoras Giovanna Garzoni, Artemísia Gentileschi e a arquiteta e pintora Plautilla Bricci.

Consuelo Lollobrigida (2012) ainda lembra que a partir do século XVII se nota também um tímido progresso na alfabetização feminina, quando o tema da educação se insere num quadro mais amplo de preocupações do Estado moderno. O problema da educação feminina é discutido desde o início do século XVI quando à tríade pregare-leggere-fardi conto (rezarler-fazer contas), são adicionadas novas "disciplinas" praticadas nos conventos, nas escolas de caridade, ou no interior das próprias família, mas com renovado vigor.

Em 1528 Baldassarre Castiglione publica a obra intitulada Il libro delCortegiano $^{16}$, em Veneza e Florença, dedicando um capítulo à mulher ideal. Consuelo Lollobrigida (2012) destaca algumas questões interessantes da obra de Castiglione: todas as qualidades e as artes indispensáveis ao cortesão são apropriadas à mulher, “[...] uma instrução de alto nível, saber pintar, tocar e cantar; escrever poesia; saber desenvolver uma conversa argumentativa e inteligente" (LOLLOBRIGIDA, 2012, p. 6). Conforme a mesma autora, a obra de Castiglione teve o mérito de difundir tais princípios em todos os estados europeus, contribuindo para disponibilizar às mulheres uma instrução mínima.

Nos diálogos do Terzo libro do Cortesão, Castiglione escreve referindose às mulheres: "Eu digo que elas devem ser consideradas tanto quanto o cortesão" (CASTIGLIONE, 1965, p. 284). Ao longo do mesmo capítulo, Castiglione exalta as virtudes relevantes que as mulheres dignas de um cortesão deveriam ter. A nobreza no modo de portar-se, a graciosidade no modo de falar, a beleza, os costumes, as habilidades, o saber, a bondade,

${ }^{16}$ CASTIGLIONE, Baldassarre. Il libro delCortegiano. A cura di Giulio Preti. Torino: Einaudi, 1965. 
e tantas outras virtudes que serão a causa do amor do cortesão pelas mulheres (CASTIGLIONE, 1965, pp. 285-286).

Lollobrigida (2012) lembra que nos estados que aderiram a Reforma Protestante, os textos de Erasmo ${ }^{17}$, que defendiam a educação de jovens mulheres em nome de um bom entendimento entre os casais e a sociedade; e de Lutero $^{18}$, cujos escritos pregavam o acesso à leitura para que todos, homens e mulheres, pudessem ler as Sagradas Escrituras; também contribuíram para o tema da alfabetização das mulheres aparecer com mais frequência a partir do século XVI.

A influência da obra de Baldassarre Castiglione é visível nos tratados de arte posteriores. Para Consuelo Lollobrigida (2012, p. 7), ao configurar o perfil da perfeita mulher de corte, Castiglione cria, involuntariamente, também o modelo da mulher artista: a seriedade, a honestidade e a graciosidade são virtudes presentes nas biografias de artistas pelo menos até o final do século XVIII. A partir de Giorgio Vasari (1563) ${ }^{19}$ quase todos os críticos que destinaram algumas páginas de seus trabalhos para abordar mulheres artistas o fizeram enfatizando os atributos ligados à virtuosidade.

Assim como outras mulheres de seu tempo, as pintoras aqui mencionadas enfrentaram os limites impostos pelos discursos misóginos hegemônicos. Entretanto, é provável que, como afirma Ilaria Pagani (2003), a cultura do renascimento tenha desenvolvido possibilidades para que, "[...] as mulheres não tanto superassem essas limitações, quanto as contornassem" (2003, p. 1).

Nesse sentido, queremos problematizar as produções da historiografia da arte recente, principalmente as obras que possuem perspectivas biográficas, pois acreditamos que esses estudos podem contribuir com as reflexões que se utilizam do conceito de gênero para pensar a atuação das mulheres no mundo da criação artística.

Dedicaremos uma atenção especial à trajetória de vida da pintora romana Artemísia Lomi Gentileschi (1593-1654). Nossa reflexão possui um recorte temporal que privilegia o período a partir do qual Artemísia se estabelece em Florença, em 1613, evento significativo para sua carreira,

\footnotetext{
${ }^{17}$ RUMMEL, Erika. Colloquidi Erasmo da Rotterdam. Milano: Editoriale Jaca Book SpA, 1998.

${ }^{18}$ LUTERO, Martinho. Obras selecionadas. São Leopoldo: Comissão Interluterana de Literatura, 1989.

${ }^{19}$ Utilizamos uma edição mais recente da obra: VASARI, Giorgio (1511-1574). Le vite dei più eccellenti scultori, pittori e architetti. Torriana: Orsa Maggiore, Ed. Integrale, 1991.
} 
pois é na cidade florentina que será oficialmente reconhecida como pintora; e seu retorno a Roma, em 1620. Em Florença o tio, Aurelio Lomi, apresentou-a à corte de Cosme II de Medici, na qual passou a atuar. A vida na corte se revelou uma experiência importante para o seu futuro: estabeleceu relações com representantes da nobreza, da política e das artes, conforme Tiziana Agnati (AGNATI, 2001, p. 8). Foi nesse período que conheceu Michelangelo Buonarroti, o Jovem, Francesco Maria Maringhi, Galileu Galilei, entre outrosmembros do círculo de intelectuais e artistas que tinham sido reunidos pelo Grão-Duque Cosme II de Medici, com quem Artemísia viria a trocar correspondência no futuro.

O catálogo da Mostra Artemisia se reveste de grande importância, pois publica um numeroso acervo visual, disponibilizando, inclusive, algumas obras de coleções particulares que não encontramos em suporte digital. A tela Cristo e la samaritana al pozzo (1637), por exemplo, foi pela primeira vez exposta ao público na Mostra Artemisia, conforme Luciano Arcangeli (2011). A imagem é um dos quadrigrandi que Artemísia cita em duas cartas enviadas, durante o outono de 1637, de Nápoles a Roma, para Cassiano dalPozzo ${ }^{20}$. Para Arcangeli (2011), o quadro é um dos maiores trabalhos de Artemísia do primeiro período napolitano da artista, que termina com sua saída para a Inglaterra, em 1638 - onde irá trabalhar junto com seu pai na realização de uma pintura no teto da Casa da Rainha (Queen's House de Inigo Jones) em Greenwich.

A publicação do catálogo contribui com os estudos sobre a trajetória de Artemísia, tendo em vista que faz referência a um rico conjuto de cartas e outros documentos escritos, bem como sua localização em inúmeros arquivos históricos de Roma, Florença, Veneza, Nápoles, Livorno e Londres. Os contextos histórico, social e cultural o século XVII são amplamente discutidos ao longo de análises que oportunizam uma intensa aproximação entre história, arte e imagem a partir da trajetória da pintora Artemísia Gentileschi. Assim, desenvolveremos uma breve análise dos capítulos dos organizadores do catálogo, Roberto Contini e Francesco Solinas (2011).

\section{Representações de Artemísia na historiografia da arte: a perspectiva de Roberto Contini}

Iniciaremos nossa análise sobre as representações de Artemísia na historiografia da arte italiana a partir do capítulo de Roberto Contini:

${ }^{20}$ LetterediArtemisia (SOLINAS, 2011b, p. 117). 
"Fino a qual segno giungessel'ingegno, e la mano d'una tal donna": geografia e rango di Artemisia Gentileschi ${ }^{21}$, discutindo se e como as questões de gênero são problematizadas pelo autor e se a ilusão biográfica é uma preocupação apresentada no texto.

O título do texto de Roberto Contini é uma frase retirada da obra de Filippo Baldinucci $(1728)^{22}$, na qual o autor escreve sobre Artemísia Gentileschi em seu volume referente às vidas dos artistas. A tradução do título "Até que ponto chegaria a capacidade técnica e a mão de uma tal mulher: percurso e posição social de Artemísia Gentileschi” denota a preocupação do autor em acompanhar a trajetória de vida da pintora e é esta questão que queremos analisar no referido capítulo.

Roberto Contini inicia o texto afirmando que ao dedicar-se à carreira de pintora, o que teria sido muito facilitado pelo papel protagonista do pai como pintor, Artemísia foi uma artista de relevância médio-alta e seu lugar nunca foi de atriz coadjuvante. Para o autor, mesmo as suas criações menos bem sucedidas refletem o seu, "talvez inato talento",23 (CONTINI, 2011, p. 36).

A este respeito acreditamos ser importante mencionar as considerações de Pierre Bourdieu (1996, p. 184) sobre a ilusão biográfica. Para Bourdieu, quando a vida é organizada a partir de uma ordem lógica e cronológica, apresentando um duplo sentido, de início ou ponto de partida, mas também como uma razão de ser, é como se a vida constituísse um conjunto coerente e orientado com um objetivo final. Ao vincular " $[. .$.$] certos acontecimentos significativos e estabelecendo entre$ eles conexões para lhes dar coerência [...]” (BOURDIEU, 1996, p. 185), Contini (2011) pode nos levar a pensar na carreira de Artemísia como um fim para o qual a profissão do pai a direcionou. Além disso, ao comentar sobre o "inato talento" de Artemísia, ainda que ponderando com o uso do advérbio "talvez", Continise insere entre os autores de uma tradição que vem do Romantismo - de exaltar a genialidade do artista, uma questão que podemos perceber com mais evidência ao longo do capítulo.

Nessa perspectiva, Giovanni Levi (1996) ressalta que uma das dificuldades para escrever a vida de um indivíduo é o modelo de racionalidade que os pesquisadores obedecem "[...] modelos que

\footnotetext{
21“Até que ponto chegaria a capacidade técnica e a mão de uma tal mulher: percurso e posição social de Artemísia Gentileschi”(CONTINI, 2011, pp. 36-50). (Tradução de minha autoria).

${ }^{22}$ BALDINUCCI, Filippo. Notizie de' professorideldisegno da Cimabue in qua. Opera postuma. Firenze: Per Santi Franchi, 1728, p. 293.

23"Persinodalle sue creazionimenoriuscite si sprigionail respiro caldo del suo forseinnato talento" (CONTINI, 2011, p. 36).
} 
associam uma cronologia ordenada, uma personalidade coerente e estável, ações sem inércia e decisões sem incertezas" (LEVI, 1996, p. 169). Entendemos que o capítulo de Contini (2011) se utiliza de um modelo pouco sensível ao "[...] caráter aberto e dinâmico das escolhas e das ações” (LEVI, 1996, p. 178), no qual a carreira de Artemísia se apresenta sem contradições, como se sua profissão fosse mais uma consequência da profissão do pai do que uma escolha da própria pintora.

No decorrer do capítulo, Contini comenta algumas obras pictóricas de Artemísia. A primeira obra documentada da pintora em Florença, mas possivelmente não a primeira a ser produzida por Artemísia na cidade, Allegoriadell'Inclinazione (Alegoria da Inclinação - 1615) foi encomendada por Michelangelo, $O$ Jovem, para a galeria da Casa Buonarroti. Um trabalho que, conforme indica Contini (2011, p. 39), era almejado pela grande maioria dos jovens artistas que atuavam nos ateliês florentinos, com idade próxima a de Artemísia, na época com 22 anos.

FIGURA 1 - Susanna

e i vecchioni (1610).

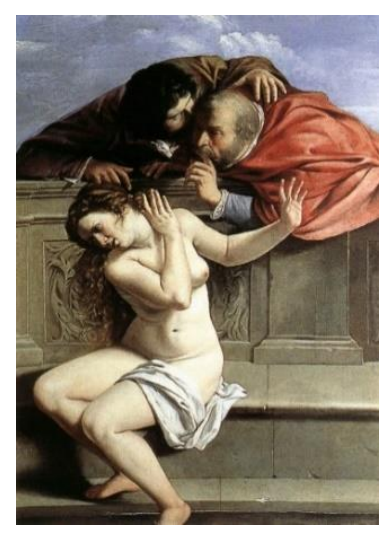

Fonte: Artemísia Gentileschi. Óleo sobre tela, 170 x 119 $\mathrm{cm}$.

Weissenstein, Pommersfelden, Alemanha.
FIGURA 2 -

Allegoriadell'inclinazione (1615).

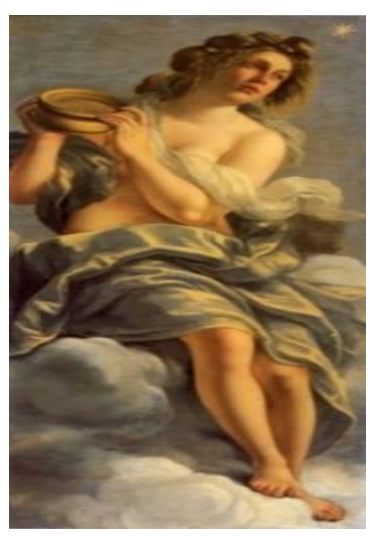

Fonte: Artemísia Gentileschi. Afresco $152 \times 61 \mathrm{~cm}$. Casa Buonarroti, Florença, Itália 
Contudo, é a tela Susanna e i vecchioni (Susana e os velhos - 1610) assinada e datada por Artemísia aos 17 anos, que testemunha seu "talento precoce", nas palavras de Roberto Contini. A imagem já foi interpretada como obra de Orazio Gentileschi, um equívoco, se considerarmos que entre os anos de 1610 e 1612, Orazio trabalhou intensamente na obra Concerto con Apollo e leMuse (Concerto com Apolo e as Musas), produzida no teto do Palazzo Pallavicini, em Roma. Além disso, não se conhecem outras obras de Orazio datadas desse período. Sabe-se que na década entre 1600 e 1610 os trabalhos artísticos desenvolvidos por Orazio exigiram que ele se ausentasse de casa diariamente. Entretanto, no decorrer desses anos, eram entregues suprimentos para pintura na casa dos Gentileschi, o que sugere que Artemísia estava ativamente envolvida com a produção pictórica, conforme afirma Judith Mann (2011, p. 57).

Datada de 1608-1609, a primeira pintura conhecida de Artemísia em Roma é uma tavoletta $^{24}$ que fazia parte de um díptico representando "A Pintura e a Poesia", de propriedade do colecionador romano Alessandro Biffi. De acordo com Maria Lucrezia Vicini (2000), em um inventário de 1637, quando Biffi vendeu sua coleção para pagar uma dívida, foram descritas, entre outras imagens, dois pequenos quadros de formato ovalado que representam “A Pintura e a Poesia”, produzidas pela mão de Artemísia, na época com 15 anos. Assim, todas essas observações nos ajudam a dar sustentação à hipótese, já aceita entre os historiadores da arte, de que a obra "Susana e os velhos" é uma tela produzida por Artemísia e não pelo pai.

O capítulo de Roberto Contini também nos chama a atenção para uma das musas de Apolo, a Dama conventaglio (Dama com leque) que faz parte da obra Concerto con Apollo e leMuse ${ }^{25}$. Uma imagem que se assemelha, em relação à estética da figura humana, à tela Cleopatra, produzida por Artemísia no mesmo período. Para Contini, é importante reconhecer que o trabalho do teto do Palazzo Pallavicini foi realizado pelas mãos tanto do pai OrazioGentileschi, como da filha Artemísia, além da participação de Agostino Tassi ${ }^{26}$.

${ }^{24}$ Pequena placa de madeira, sua atual localização é num acervo particular de Florença.

${ }^{25}$ Uma obra encomendada por Scipione Borghese. De acordo com Annemarie Boetti, o projeto geral da galeria do palácio de Borghese é de Tassi: uma estrutura ilusionista que irrompe através do teto abobadado com voltas crescentes e varandas rosadas como a aurora (BOETTI, 2004, p. 130).

${ }^{26}$ Agostino Tassi foi acusado de desvirginar forçadamente a jovem Artemísia Gentileschi em 1611. O pintor toscano foi julgado no processo crime de 1612 
A "Dama com leque" assistindo ao concerto foi interpretada como um retrato de Artemísia, que teria sido modelo do pai. Entretanto, o mesmo historiador da arte (2011, p. 40) ressalta que a imagem pode ser um autorretrato produzido por Artemísia, considerando sua evidente semelhança com outras obras da pintora como, por exemplo, Allegoriadell'Inclinazione, Maddalena Penitente, Cleopatrae Susanna.

FIGURA 3: Dama conventagliodal concerto com Apollo e leMuse (1611)

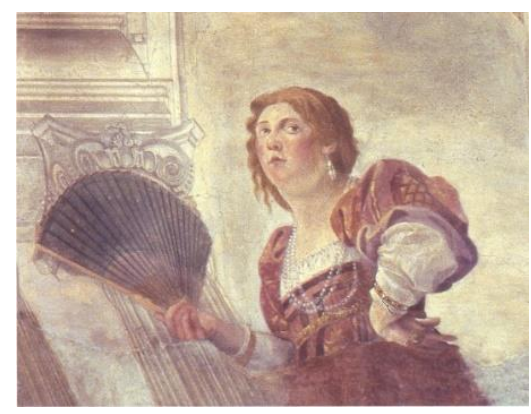

Fonte: Orazio Gentileschi e Agostino Tassi.PalazzoPallavicini, Roma.

FIGURA 4: Cleopatra (1611-12)

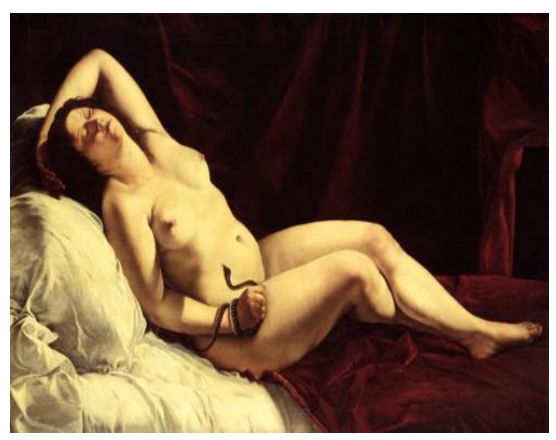

Fonte: Artemísia Gentileschi. Collezioneprivata, Roma.

Nos dois exercícios realizados por Contini (2011, p. 40), ao analisar as obras "Susana e os velhos" e "Concerto com Apolo e as musas", o autor se permite lançar-se a novos desafios de pesquisa, escavando novas possibilidades. Tal perspectiva também se

"Estupro e Libidinagem. Em favor da Cúria [Romana] e do Fisco [Tesouro Romano]" e condenado ao exílio por cinco anos - pena que não cumpriu. O processo foi publicado por EvaMenzio (2004). 
apresenta nos estudos de Sabina Loriga (2011), quando a autora ressalta: "E é justamente quando se encontra numa posição incômoda, sob a superfície, que o historiador tem a possibilidade de verificar a pertinência da questão que colocou, de corrigi-la e - por que não? - de encontrar outra coisa, que não esperava" (LORIGA, 2011, p. 120).

Nesse sentido, Roberto Contini apresenta problemas de pesquisa diferentes das gerações que o precederam, pois considera Artemísia uma pintora e não apenas uma discípula e modelo do pai, como outros o fizeram, a exemplo de Roberto Longhi (1916). Ao revelar novas hipóteses para o trabalho com a análise de imagens produzidas por Artemísia e Orazio Gentileschi, Roberto Contini (2011, p. 41) nos apresenta também suas intuições em relação ao trabalho com obras de arte, intuições impressionadas pelas fontes imagéticas. Além disso, o autor não deixa de se utilizar também dos recursos imaginativos disponibilizados ao biógrafo, “[...] que deve refazer um universo perdido segundo sua intuição e talento criador" (DOSSE, 2009, p. 55).

Dando sequência ao estudo sobre a trajetória de vida de Artemísia, Roberto Contini comenta o período entre os anos de 1613 e 1621, quando a pintora passa a viver em Florença com o tio Aurélio Lomi e o marido Pietro Antônio Stiattesi. Sua ida para a cidade florentina ocorre após o casamento de conveniência organizado pelo pai, em função da situação de exposição pública na qual se encontrava Artemísia: "desvirginada", e o fim do processo crime por desvirginamento encerrado após cinco meses de interrogatórios e acareações.

Em Florença, Artemísia não recebeu encomendas de membros eclesiásticos, nem participou de afrescos coletivos. Todavia, Contini (2011, p. 41) destaca sua notável atuação como pintora na Corte da família Medici - um feito, até então, inédito para uma mulher. O mesmo autor ainda afirma que não se conhecem imagens de outros artistas desse período que tenham produzido madonas, santas e heroínas com igual destaque para o volume dos corpos das personagens, o que só aconteceria na década de 1630, quando imagens de importante refinamento surgiram, porém, infinitamente menores no que diz respeito ao realismo e à perspectiva tridimensional das figuras humanas.

Quando se refere ao "feito inédito" de Artemísia, Roberto Contini (2011, p. 41-42) não chega a desenvolver uma reflexão a partir do 
conceito de gênero. Além disso, no texto de Contini não encontramos questionamentos sobre a luta contra a "hierarquia dos sexos", um termo utilizado por Natalie Z. Davis (1997). Ao perguntar-se sobre as contribuições de Artemísia nas obras do pai, teria sido relevante o autor problematizar as questões de gênero.

Acompanhando a proposta de Davis (1997), poderíamos dizer que, de forma semelhante às trajetórias das três mulheres estudadas pela autora, Artemísia também encontrou "coisas nas margens". A pintora soube tirar o máximo proveito de sua situação ainda que ocupasse um lugar nas margens ${ }^{27}$. Se Artemísia não foi "honrada o suficiente", para produzir obras em igrejas durante sua atuação em Florença, foi ousada ao tentar fazer algo novo no que se refere às mulheres, como o fizeram Glikl, Marie e Maria Sibylla. Utilizamonos das palavras de Davis para pensar a trajetória de Artemísia: “[...] suas histórias revelam outras possibilidades de vida no século XVII. [...] Em cada um dos casos a pessoa se libertou um pouco das restrições das hierarquias europeias" (DAVIS, 1997, p. 195196).

Após comentar uma série de imagens produzidas por Artemísia em Florença, Roberto Contini encaminha a finalização de seu texto destacando que tanto na cidade florentina, como em Roma e em Veneza, não há evidências de trabalhos da pintora em igrejas. Para Contini, essa ferida em sua vocação de artista universal ${ }^{28}$, foi rapidamente curada com sua chegada em Nápoles, onde em 1630 pintou Annunciazione (Anunciação) na igreja San Giorgio dei Genovesi ${ }^{29}$,e onde também dará início a uma fase de forte empenho na produção de imagens de natureza morta e com animais em pose.

\section{Representações de Artemísia na historiografia da arte: a perspectiva de Francesco Solinas}

Dando sequência ao nosso trabalho sobre as representações de Artemísia na historiografia da arte italiana, analisaremos, neste subtítulo do texto, o capítulo de Francesco Solinas (2011a), intitulado Ritorno a Roma: $1620-1627^{30}$, no qual encontramos uma

\footnotetext{
${ }^{27}$ Uma frase inspirada no texto introdutório de Davis (1997, p. 13).

28“Questaferitaalla sua vocazionedi artista universale”(CONTINI, 2011, p. 47). (Tradução de minha autoria).

${ }^{29}$ Localizada no centro histórico de Nápoles. Atualmente a obra Annunciazione (1630) está no acervo do MuseoNazionalediCapodimonte.

${ }^{30}$ Retorno a Roma (SOLINAS, 2011a, pp. 79-95). (Tradução de minha autoria).
} 
escrita de caráter biográfico. O historiador da arte se dedica ao estudo da trajetória de Artemísia no período em que a pintora abandonou Florença e voltou para sua cidade natal, Roma, de onde havia partido com o marido Pietro Antônio Stiattesi, sete anos antes, em 1613.

Nesse sentido, o capítulo de Francesco Solinas (2011a) dá sequência ao período estudado por Roberto Contini, cujo recorte temporal privilegia a década anterior a 1620. As principais fontes utilizadas pelo pesquisador são as cartas de Artemísia, às quais tivemos acesso através da publicação da correspondência ${ }^{31}$, não apenas da artista, mas também de seu marido e de diversos mecenas com quem Artemísia negociou suas obras. Além disso, Solinas também se utiliza de diversas pinturas produzidas no período entre 1620 e 1627, época em que Artemísia residiu em Roma.

De acordo com Solinas, a saída repentina de Artemísia da cidade florentina, em 1620, se deu devido a questões financeiras. O acúmulo de dívidas decorrente de um contrato de trabalho mal pago pelo Grão-Duque Cosme II de Medici, que se encontrava muito doente e debilitado devido à tuberculose, trouxe problemas econômicos e sua situação em Florença ficou insustentável, conforme declara Solinas (2011a, p. 79).

O mesmo autor ainda ressalta a necessidade de uma licença concedida pelo Grão-Duque para um artista da corte sair da cidade florentina legalmente. Todavia, o consentimento do líder político não era o suficiente para se obter a autorização para fazer uma viagem, no caso de uma mulher. Segundo Solinas, com exceção das viúvas mais ricas e poderosas, era apenas sob a tutela de um homem, marido, pai, irmão, cunhado ou filho, que se autorizava uma viagem como aquela realizada em 1620 por Artemísia, cujo marido a acompanhou no percurso (SOLINAS, 2011a, p. 80).

Para interromper seu contrato de trabalho com o Grão-Duque, Artemísia escreveu uma carta, datada de 10 de fevereiro de $1620^{32}$, a Cosme II de Medici, anunciando sua intenção de passar alguns meses em Romae justificou sua viagem mencionando problemas familiares. Entretanto, para Solinas, o argumento da pintora foi um pretexto para obter a autorização do Grão-Duque, pois na carta

\footnotetext{
${ }^{31}$ Publicação organizada por Francesco Solinas (2011b).

${ }^{32}$ LetterediArtemisia (SOLINAS, 2011b, p. 27). (Tradução de minha autoria)
} 
enviada ao amigo Francesco Maria Maringhi ${ }^{33}$ (1593-1653), escrita no vilarejo de Prato, durante a viagem para Roma, Artemísia afirmou que não retornaria à Florença ${ }^{34}$. A cidade com vida artística e intelectual intensa, na qual Artemísia chegou com o marido em 1613, já não garantia sucesso econômico como antes e os pagamentos das encomendas já não eram tão privilegiados para os artistas da corte.

De acordo as pesquisas de Solinas (2011a, p. 84), antes de voltar para Roma, Artemísia havia dado à luz a quatro filhos, nascidos entre os anos de 1613 e 1618 -Giovan Battista, Cristofano, Prudenzia e Lisabella.O primogênito e a caçula já haviam falecido em 1620. Quando Artemísia e o marido saíram de Florença, os dois filhos Cristofano e Prudenzia ficaram sob os cuidados de Francesco Maria Maringhi, conforme indica a carta de 13 de fevereiro de 1620, quando a pintora solicitou que Maringhi lhe enviasse os filhos com urgência. Artemísia pediu que o amigo lhe mandasse também alguns quadros inacabados, encomendados pelo GrãoDuque, os quais também estavam na residência florentina de Maringhi.

Em Florença, Artemísia havia alcançado prestígio com obras como Judite e a criada, as duas versões de Judite degolando Holofernes, e as três versões de Madalena, por exemplo.

FIGURA 5: Giuditta e la fantesca (1613-1614)

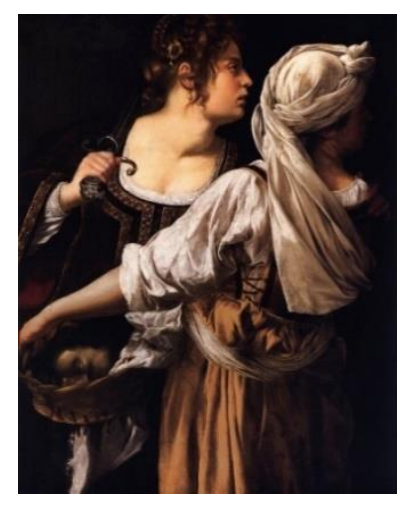

Fonte: Artemísia Gentileschi. Palazzo Pitti, Florença.

\footnotetext{
${ }^{33}$ Pertencente a uma antiga família de aristocratas florentinos. Proprietário de um discreto capital e de inúmeros imóveis e terras, conforme Solinas (2011a, p. 81).

${ }^{34}$ LetterediArtemisia (SOLINAS, 2011b, p. 33). (Tradução de minha autoria)
} 
FIGURA 6: Giuditta decapita Oloforne(1620-1621)

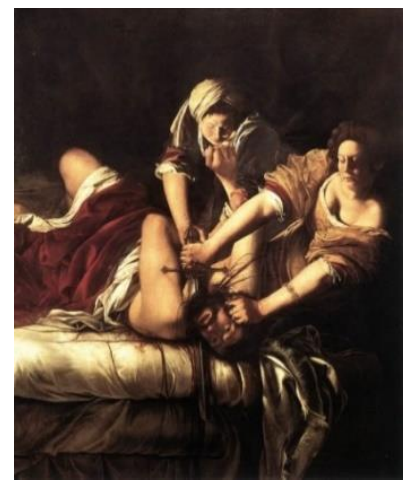

Fonte: Artemísia Gentileschi.Galleria degli Uffizi, Florença.

Entretanto, de acordo com Solinas (2011a, p. 84), as repentinas mudanças no gosto da corte e o agravamento da doença de Cosme II de Medici contribuíram para o aumento das dívidas da pintora, principalmente com instrumentos de trabalho, o que pode ter contribuído para sua partida da cidade florentina.

As considerações de Norbert Elias (1994, p.22) sobre a importância das redes de relações entre sociedade e indivíduos nos ajudam a pensar a trajetória de Artemísia. Para Elias (1994), cada pessoa está ligada a outras por laços invisíveis, sejam estes laços de trabalho, propriedade, instintos e afetos. São esses laços que constituem as redes em constante movimento, como um tecer e destecer ininterrupto das ligações. Conforme Elias (1994), é assim que efetivamente cresce um indivíduo, partindo de uma rede de pessoas que existia antes dele para uma rede que ele ajuda a formar.

Nessa perspectiva, se pensarmos o contexto do qual tratamos como uma rede, a família Medici pode ser pensada como um dos principais elos que unem os demais fios constituídos pelos artistas da corte. Uma rede que já existia, se considerarmos que o tio de Artemísia, Aurélio Lomi ${ }^{35}$, fazia parte do grupo de artistas que trabalhava para o Grão-Duque, e que a jovem pintora ajudou a formar a partir de sua chegada à cidade florentina, quando passou a atuar como membro da corte.

${ }^{35}$ Os irmãos Aurélio, Baccio e Orazio, filhos de Giovan Battista Gentileschi alias Lomi, atuaram desde cedo no mundo das artes pictóricas. Aurélio e Orazio optaram por carregar apenas uma parte do sobrenome, leia-se Aurélio Lomi e Orazio Gentileschi, conforme Cristine Tedesco (2013). 
Norbert Elias (1994, p. 23) nos adverte de que toda pessoa está presa por viver em dependência funcional de outras, ela é um elo nas cadeias que ligam outras pessoas, assim como todas as demais, são elos nas cadeias que as prendem. Tais cadeias, porém, são elásticas e mutáveis. Nesse sentido, o agravamento da tuberculose do Grão-Duque Cosme II de Medici desestabilizou o ambiente e outras possibilidades se apresentaram para Artemísia, o que nos permite pensar nas margens de liberdade dos indivíduos como "[...] uma jaula flexível e invisível dentro da qual se exercita a liberdade condicionada de cada um" (GINZBURG, 2006, p. 20).

A "flexibilidade da jaula", à qual se refere Carlo Ginzburg (2006), pode ter contribuído para um novo rumo na vida profissional de Artemísia. A produção pictórica da pintora em Roma representa um importante legado, hoje disponível em acervos de diversos países, pois o retorno à cidade colaborou para o desenvolvimento de uma segunda etapa em sua carreira, o que lhe traria fama internacional, principalmente depois de trabalhos como Jael e Sísara $(1620)^{36}$.

O ano da chegada de Artemísia a Roma foi um período de perdas e conquistas para a pintora, declara Solinas. A perda do filho Cristofano, na época com cinco anos, é relatada numa carta de onze de abril de 1620, endereçada a Francesco M. Maringhi ${ }^{37}$. Para o mesmo autor, a referida carta está entre as mais comoventes de sua correspondência ${ }^{38}$.

É a partir de 1620 que Artemísia passa a receber frequentes encomendas de cardeais e jovens mulheres de famílias nobres, que a procuravam para encomendar retratos, afirma Solinas. O historiador da arte ressalta que para dar conta da intensa rotina de trabalho no ateliê, Artemísia contratou assistentes que lhe preparavam as telas e as cores, como foi o caso de Alessandro Bardelli (SOLINAS, 2011a, p. 88).

Outros indícios que sugerem o sucesso da pintora em Roma são as cartas enviadas por seu marido Pietro A. Stiattesi ao amigo Maringhi, nas quais são relatadas algumas questões importantes, como por exemplo, sua mudança para um apartamento maior, em junho de 1620. Stiattesi ainda expõe ao amigo que as coisas

\footnotetext{
${ }^{36}$ Uma obra de autoria reconhecida em 1978 quando ÁgnesSzigheti percebeu a assinatura de Artemísia na tela, conforme destaca Solinas (2011a, p. 87).

${ }^{37}$ LetterediArtemisia (SOLINAS, 2011b, p. 53). (Tradução de minha autoria)

38 "Una letteratralepiùcommoventidel suo carteggio".LetterediArtemisia (SOLINAS, 2011b, p. 53). (Tradução de minha autoria).
} 
estavam muito bem em Roma. ${ }^{39}$ De acordo com Francesco Solinas (2011a, p. 88), o mercado de artes em expansão na região de Roma contribuiu significativamente para o aumento do número de encomendas recebidas no ateliê de Artemísia, ao longo da década de 1620 .

A partir de 1623 não há mais indícios da presença de Pietro A. Stiattesi junto à sua esposa Artemísia. Segundo os estudos de Solinas (2011a, p. 90), a pintora continuou vivendo em seu apartamento, conforme o censo romano: com a "senhora Artemísia Lomi romana pintora" moram os dois irmãos Giulio e Francesco, a filha Prudenzia e dois criados.

O censo efetuado durante a quaresma de 1626 foi o último testemunho da presença de Artemísia em Roma, com a filha e a criada Domenica, conforme Michele Nicolaci (2011, p. 263). Entre 1627 e 1628, sua presença é documentada em Veneza, onde a pintora viveu alguns anos e de onde partiu em 1630 fugindo de uma epidemia de peste, passando a viver em Nápoles (NICOLACI, 2011, p. 264).

A respeito do período em que Artemísia viveu em Roma, Francesco Solinas (2011a) ressalta que a pintora seguiu seu próprio caminho, graças a Cassiano dalPozzo $(1588-1657)^{40}$, que a introduziu num grupo de artistas através do qual recebeu encomendas importantes. Tal afirmação de Solinas nos encaminha para uma reflexão acerca das margens de liberdade dos indivíduos. Seguindo a ideia do autor, é como se Artemísia não fosse responsável pelo próprio sucesso, o qual alcançou: "graças à dalPozzo". Solinas (2011a, p. 82) ainda menciona Cristofano Allori (1577-1621), colega pintor cuja relação de amizade com Artemísia teria facilitado a entrada da pintora na Academia de Desenho de Florença. Os momentos da trajetória de Artemísia, os quais o autor nos apresenta como decisivos, são acompanhados de intervenções de indivíduos que teriam garantido seu bem sucedido futuro.

Por outro lado, finalizando o capítulo intitulado Retorno a Roma, Solinas se refere à Artemísia como:

Filha de um dos mais respeitados pintores do seu tempo, crescida no ambiente da surpreendente pompa do reino

39"Finalmente le cose civannomellio assai diquellocipensamo". LetterediArtemisia(SOLINAS, 2011b, p. 76). (Tradução de minha autoria).

40 Membro de uma família de nobres. Prestou serviços a corte do cardeal Francesco Barberini e foi colecionador de arte. 
aburguesado e das suntuosas antessalas dos cardeais, provavelmente presente, como um rapaz, sobre os andaimes dos locais de trabalho de maior prestígio do pai, desde muito jovem a talentosa pintora lutou para fazer valer aquele seu natural, extraordinário talento artístico ${ }^{41}$ (SOLINAS, 2011a, p. 90).

O autor nos apresenta uma Artemísia predestinada ao sucesso. Dotada de um talento artístico extraordinário, filha de um pintor de prestígio, inserida no ambiente de produção pictórica, encontrou as pessoas certas para the abrir caminho e lhe oferecer grandes oportunidades. Contudo, ao problematizarmos estas questões, podemos nos perguntar sobre as margens de liberdade e escolhas dos indivíduos. Para tal reflexão utilizamos as discussões de Giovanni Levi. Para o autor, "[...] nenhum sistema normativo é suficientemente estruturado para eliminar qualquer possibilidade de escolha consciente, de manipulação ou de interpretação das regras, de negociação" (LEVI, 1996, p. 179-180). Não há como saber o que determinou a inserção e sucesso de Artemísia no mundo da pintura, não há como dizer se foi por influência do pai, do tio, de outros indivíduos como Cassiano dalPozzo e Cristofano Allori ou ainda fruto de seu "extraordinário talento artístico". Mas é bem provável que "[...] a existência irredutível de uma certa liberdade" (LEVI, 1996, p. 180), tenha possibilitado determinadas escolhas feitas por Artemísia e contribuído para sua atuação na Corte da família Medici, sua oficialização na Academia de Desenho de Florença e consolidação como pintora na Península Itálica, onde trabalhou até os últimos anos de sua vida.

Também chamamos a atenção para outras expressões de Francesco Solinas, mencionadas na citação acima, como por exemplo: "[...] desde muito jovem" (SOLINAS, 2011a, p. 90). A passagem remete ao que Pierre Bourdieu chamou de criação artificial de sentido. $\mathrm{O}$ que consiste em escrever uma história de vida "[...] como o relato coerente de uma sequência de acontecimentos com significado e direção" (BOURDIEU, 1996, p. 185). É preciso destacar a importância de considerarmos que as fontes nos apresentam os fatos prontos e não os processos de elaboração de decisão vividos pelos indivíduos, como nos indica Levi (1996, p. 168-169).

\footnotetext{
$\begin{array}{lllll}{ }^{41} \text { Figliadi uno dei } & \text { piùquotatipittoridel suo } & \text { tempo, } \\ \text { cresciutanell'auradellastupefacente } & \text { pompa delregnoborghesiano } & \text { e }\end{array}$ dellesontuoseanticamerecardinalizie, probabilmente presente, come unragazzo, sui ponteggi dei piùprestigiosicantieridelgenitore, $\sin$ da giovanissimalatalentuosapittriceavevalottato per affermarequel suo naturale, straordinario talento artistico(SOLINAS, 2011a, p. 90). (Tradução de minha autoria).
} 
Neste aspecto, acreditamos que é necessário pensar para além do "extraordinário talento artístico" de Artemísia e considerar que as decisões que nos parecem importantes hoje, podem ter sido tomadas pela pintora em momentos de incerteza. Tais decisões podem ter desencadeado outras ações, sem que estas tenham sido necessariamente planejadas com um objetivo final. Além disso, há também a interferência de fatores do acaso e ainda as influências das redes de relações que Artemísia construiu ao longo de sua trajetória, as quais podem ter contribuído para sua inserção em determinados espaços por onde circulou. Por isso, torna-se indispensável pensar nestes múltiplos fatores que produziram resultados, os quais, por sua vez, produziram as fontes.

Na citação anterior, Francesco Solinas comenta que Artemísia esteve "[...] presente como um rapaz, sobre os andaimes dos locais de trabalho de maior prestígio do pai" (SOLINAS, 2011a, p. 90). Todavia, o autor não aborda as questões de gênero, o que acreditamos ser importante para problematizar a trajetória de Artemísia.

Ao refletirmos sobre a atuação das mulheres no mundo masculinizado da produção artística, nos utilizamos dos estudos de Rachel Soihet (2010). A autora explica que diferentes discursos reproduziam a noção de que as artes "[...] seriam formas de criação do mundo. Como poderiam as mulheres, capazes apenas de copiar, traduzir e interpretar, terem condição para fazê-lo?" (SOIHET, 2010, p. 209). Nesse sentido, é bem provável que Artemísia tenha vivenciado desigualdades de gênero como outras mulheres de seu tempo. Contudo, pode ter desenvolvido estratégias para cruzar os limites dos sistemas normativos de sua época, os quais “[...] jamais estão isentos de contradições" (LEVI, 1996, p. 180).

As considerações de Michelle Perrot (2005) também nos ajudam a entender essa questão. Para a autora, assim como o poder, os espaços de resistência não são sempre explícitos, nem sempre ocorrem no confronto. Perrot (2005, p. 263) ressalta que é necessário considerar os poderes multiplicados na sociedade, não esquecendo os contra poderes através dos quais as mulheres subvertem seus papéis aparentes.

Encerramos a análise do capítulo "Retorno a Roma"de Francesco Solinas (2011a), salientando que em diversos momentos do texto o autor busca uma unidade de sentido ao apresentar-nos a trajetória de Artemísia. Para Sabina Loriga, alcançar tal objetivo torna-se 
evidentemente muito improvável, tendo em vista "[...] a natureza descontínua e provisória do real” (LORIGA, 1998, p. 246).

\section{Considerações finais}

Por meio do presente artigo, podemos dizer que nossas problematizações buscaram valorizar os espaços entre a vida e a obra de Artemísia Gentileschi. A análise dos capítulos de Roberto Contini e Francesco Solinas, ambos com perspectivas biográficas, permitiu evidenciarmos que as tensões entre o real e o imaginativo se fazem presentes nos dois textos.

Ainda que não se possa restituir a complexidade da vida de um invivíduo, mesmo porque uma vida está muito além dos vestígios do passado que restaram dela, o pesquisador pode se utilizar dos fragmentos de uma trajetória para desenvolver hipóteses não reducionistas e abrircaminho para abordagens onde os indivíduos, suas relações, experiências e visões de mundo possam tornar evidentes aspectos antes negligenciados ou considerados menos relevantes.

Acreditamos ter contribuído com os estudos sobre astrajetórias das mulheres na produção da arte, ao problematizarmos os trabalhos dos histriadores da arte Roberto Contini e Francesco Solinas. Procuramos salientar que a atuação de Artemísia não a torna nem vítima nem heroína de sua época, mas sim uma mulherde seu tempo que não deixou de viver em lugares desafiadores. Os estudos sobre mulheres como Artemísia Gentileschi, Lavínia Fontana, Elisabetta Sirani e Sofonisba Anguissola, por exemplo, nos indicam uma perspectiva para além de um femininio fragilizado e preso ao lar, pois construíram espaços de atuação que podem desestabilizar representações pré-estabelecidas sobre a atuação das mulheres no mundo da criação.A partir das trajetórias dessas mulheres, nos perguntamos que outras histórias podemos escrever: uma outra história da arte, da pintura e das mulheres, tendo em vista limites mais flexíveis para as fronteiras de gênero.

\section{Referências}

AGNATI, Tiziana. "La fortuna di Artemisia". Art Dossier. Firenze, Giunti, n. 172, pp. 5-50, novembre, 2001. 
ALBERTI, Leon Battista. De pintura. Tradução Antônio da Silveira Mendonça. 2 ed. Campinas: Editora da Unicamp, 1999.

ARCANGELI, Luciano. Catalogo Artemisia Gentileschi. In. CONTINI, Roberto; SOLINAS, Francesco. Artemisia Gentileschi. Storiadi una passione. Catalogo della mostra(Milano, 22 settembre 2011-30 gennaio 2012). Milano: 24 ORE Cultura, 2011, pp. 130-258.

BALDINUCCI,Filippo. Notizie de' professorideldisegno da Cimabue in qua. Opera postuma. Firenze: Per Santi Franchi, 1728. Digitalizado por Oxford UniversityGalleries (2007). Disponível em:

<https://books.google.com.br/books?id=jVsGAAAAQAAJ\&prints ec $=$ frontcover\&hl $=$ pt -

$\mathrm{BR} \&$ source $=$ gbs_ge_summary_r\&cad $=0 \# \mathrm{v}=$ onepage $\& \mathrm{q} \& \mathrm{f}=\mathrm{false}>$ Acesso em 25 de setembro de 2015.

BOETTI, AnnemarieSauzeau. "Nota suunafresco". In.MENZIO, Eva. (Org.). Lettere precedute da «Atti di un processo per stupro».Roma: Abscondita, 2004.

BOURDIEU, Pierre. “A ilusão biográfica”. In: AMADO, Janaína e FERREIRA, Marieta de Moraes (orgs.). Usos \& abusos da história oral. Rio de Janeiro: Ed. FGV, 1996.

BUFFON, Dolvino Antônio.Papas: biografias.Porto Alegre: EST, 1999.

CASTIGLIONE, Baldassarre. Il libro delCortegiano. A cura di Giulio Preti. Torino: Einaudi, 1965.

CONTINI, Roberto; SOLINAS, Francesco. (Org.). ArtemisiaGentileschi.Storiadi una passione. Catalogo della mostra (Milano, 22 settembre 2011- 30 gennaio 2012). Milano: 24 ORE Cultura, 2011a.

CONTE; Floriana. Nota a margine delritrattodi Vincenzo Ferdinando RanuzzidiElisabettaSirani. Iconographica XII, 2013, pp. 186-189.

DAVIS Natalie Zemon. Nas Margens: três mulheres do século XVII.São Paulo: Companhia das Letras, 1997.

DOSSE, François. O desafio biográfico. Escrever uma vida. São Paulo: EDUSP, 2009.

ELIAS, Norbert. A sociedade dos indivíduos. Rio de Janeiro: Jorge Zahar, 1994. 
GINZBURG, Carlo. O queijo e os vermes: o cotidiano e as ideias de um moleiro perseguido pela inquisição. São Paulo: Companhia das letras, 2006.

GOLZIO, Vicenzo. Il seicento e ilsettecento. Torino: Utet, 1950.

LEVI, Giovanni. "Usos da biografia". In: AMADO, Janaína e FERREIRA, Marieta de Moraes (Orgs.). Usos \& abusos da história oral. Rio de Janeiro: Ed. FGV, 1996.

LOLLOBRIGIDA, Consuelo. Di mano donnesca. Donneartistedal XVI al XX secolo. Roma: Andreina\&ValneoBudaiEditori, 2012.

LONGHI, Roberto. "Gentileschi padre e figlia”. In. L'Arte, n. 19, 1916, pp. 245-314.

LORIGA, Sabina. O pequeno X. Da biografia à história. Belo Horizonte: Autêntica, 2011.

"A biografia como problema". In: REVEL, Jacques (org). Jogos de escalas: a experiência da microanálise. Rio de Janeiro: Ed. FGV, 1998.

LUTERO, Martinho. Obras selecionadas. São Leopoldo: Comissão Interluterana de Literatura, 1989.

MAFFEIS, Rodolfo. "Di un tuono e di una evidenza che spira terrore". Artemisia Gentileschi a Firenze: 1612-1620, pp. 62-78. In. CONTINI, Roberto; SOLINAS, Francesco. Artemisia Gentileschi. Storiadi una passione. Catalogo della mostra (Milano, 22 settembre 2011-30 gennaio 2012). Milano: 24 ORE Cultura, 2011.

MALVASIA, Carlo Cesare. Felsinapittrice:vite de pittori Bolognesi. Tomo primo. Bologna: Per l'Erededi Domenico Barbieri, 1678. Digitalizado pela Universidade Complutense de Madri (2010). Disponível em: $<$ https://books.google.com.br/books?id=AIUenS1UUBMC\&printse $\mathrm{c}=$ frontcover\&hl=pt-

BR\&source $=g b s \_g e \_s u m m a r y \_r \& c a d=0 \# v=$ onepage $\& q \& f=$ false $>$ Acesso em 25 de setembro de 2015.

MANGUEL, Alberto. Lendo imagens: uma história de amor e ódio. São Paulo: Companhia das Letras, 2001.

MANN, Judith. "Artemisia Gentileschi nella Roma di Orazio e dei caravaggeschi: 1608-1612”. In. CONTINI, Roberto; SOLINAS, Francesco. Artemisia Gentileschi. Storiadi una passione. Catalogo della mostra (Milano, 22 settembre 2011-30 gennaio 2012).Milano: 24 ORE Cultura, 2011, pp. 51-61. 
NICOLACI, Michele. "Profilo biografico di Artemisia Gentileschi. Roma 1593 - Napoli dopo il 1654". In. CONTINI, Roberto; SOLINAS, Francesco. Artemisia Gentileschi. Storiadi una passione. Catalogo della mostra (Milano, 22 settembre 2011-30 gennaio 2012). Milano: 24 ORE Cultura, 2011, pp. 258-269.

NOCHLIN, Linda. "Why have there been no great women artista", pp. 42-69. In APOSTOLOS-CAPPADONA, Diane; EBERSOLE, Lucinda. (Org.) Women, creativity and the arts.Criticalandautobiographical perspectives. Nova Iorque: Continuum, 1997). [Publicado pela primeira vez em 1971 na revista Art News].

PAGANI, Ilaria. "Cultura artistica al femminile tra XVI e XVII secolo". Storiadelmoondo, n. 4, 24 febbraio 2003.

PERROT, Michelle. As mulheres ou os silêncios da história. Bauru-SP: Edusc, 2005.

PICINARDI, Gio Luigi. Il pennellolagrimato: orazione fúnebre. Con varie poesie. Bologna: Per GiacomoMonti, 1665. Disponível em: $<$ https://archive.org/details/ilpennellolagrim00pici> Acesso em 25 de setembro de 2015.

PIZZAGALLI, Daniela. La signora della pittura. Vita di Sofonisba Anguissola gentildonna e artista nel Rinascimento. Milano: Rizzoli, 2003.

RUMMEL, Erika. Colloquidi Erasmo da Rotterdam. Milano: Editoriale Jaca Book SpA, 1998.

SOIHET, Rachel. "Michelle Perrot". In.: LOPES, Marcos Antônio; MUNHOZ, Sidnei J. (Orgs.) Historiadores de nosso tempo. São Paulo: Alameda, 2010, pp. 193-212.

SOLINAS, Francesco Ritorno a Roma: 1620-1627. In. CONTINI, Roberto; SOLINAS, Francesco. (Org.). ArtemisiaGentileschi.Storiadi una passione. Catalogo della mostra (Milano, 22 settembre 2011- 30 gennaio 2012). Milano: 24 ORE Cultura, 2011a, pp. 79-95. Arte, 2011b. (Org).LetterediArtemisia. Roma: De Luca Editori d'

TEDESCO, Cristine. "E non dite chedipingeva come unuomo": história e linguagem pictórica de Artemísia Lomi Gentileschi entre as décadas de 1610 e 1620 em Roma e Florença. 2013. 192f. Dissertação (Mestrado) - Programa de Pós-Graduação em História. Universidade Federal de Pelotas, Pelotas. 
VASARI, Giorgio (1511-1574). Le vite dei più eccellenti scultori, pittori e architetti. Torriana: Orsa Maggiore, Ed. Integrale, 1991.

VICINI, Maria Lucrezia. Orazio e ArtemisiaGentileschiallaGalleriaSpada. Padre e figlia a confronto. Roma: GalleriaSpada, 2000.

VICENTE,Lowndes Filipa. "A arte sem história"- mulheres artistas (Sécs. XVI-XVIII). ARTIS. Revista do Instituto de História da Arte da Faculdade de Letras de Lisboa, n. 4, 2005.

Recebido em 25/11/2015

Aprovado em 30/12/2015 